\title{
Collecting Data About the Impact of School Libraries on Education, at International Level, in Developing, Emerging and Developed Countries
}

\author{
Helen Boelens \\ ENSIL Foundation, The Netherlands, and Henk van Dam, Senior Project Officer, \\ Royal Tropical Institute, KIT Information \& Library Services, Amsterdam, The \\ Netherlands.
}

\begin{abstract}
This paper describes "work in progress". It outlines attempts being made by the IASL Research SIG, the ENSIL Foundation and the Royal Tropical Institute in Amsterdam to collect consistent data about school libraries in developing, emerging and developed countries, using an international definition of what a school library actually is. During a meeting of the IASL Research SIG on 24 January 2012 it was agreed that a set of simple questions (approx. 10 questions for each group) which could be answered by pupils, teachers, school librarians and school leaders in different countries throughout the world should be developed. Sets of questions are now being reviewed by a selected group of school library practitioners and academics and by a small sub-committee of the Research $S I G$. Using the agreed sets of questions, preliminary data will then be collected by a number (school) library associations or other affiliated organizations in different parts of the world. Initial progress and results will be presented. It is to be hoped that some (initial) useful data and comparisons will demonstrate the international scope and impact of school libraries to all stakeholders, at international level.
\end{abstract}

\section{Introduction}

As outlined in the Abstract, this research is attempting to collect consistent data about school libraries in developing, emerging and developed countries, using an international definition of what a school library actually is. It is being carried out by the research team of the IASL Research SIG, the ENSIL Foundation and the Royal Tropical Institute (KIT) in Amsterdam.

\section{Research questions}

The IASL Research SIG has been approached by groups of school library practitioners, asking for data about the impact of school librarianship on education in the specific part of the world in which they work. Is it possible to collect data about the impact of school libraries on education, at international level, using an international definition of what a school library actually is? Can comparisons then be made? 
Is it possible to carry out this study in co-operation with the a divergent group of institutions including (school) library associations, the IASL, the IFLA SLRC Section, ENSIL and the KIT?

What kinds of questions will be asked, which are applicable to school libraries that operate under many different circumstance and in divergent cultural settings?

How will data be collected from different parts of the world? Timeline for data collection.

\section{Methodology/Process}

- Meetings with interested parties to discuss this research proposal.

- Selection of an international definition of what a school library actually is.

- Preparation of sets of questions to be answered by

○ Students

- Teachers

- School library practitioners

- School principals.

- Initial collection of data from a small (selected) group.

- Examination of the data which has been received.

- Conclusions to the first part of the study and presentation of results.

- If warranted by the conclusions which are reached in (6) above, the study will continue to collect data in more countries and make further comparisons.

\section{Recent developments}

It should be noted that during March 2012, the membership of the IASL Research Team was reviewed. An attempt was made to achieve a balance in the team, so that all IASL regions were represented. Colleagues who were already part of the team were asked whether or not they wished to continue this work. Also, the President of the IASL and all the regional directors were approached and asked to nominate prospective team members. These people should be researchers who had demonstrated an interest in school libraries. The IASL President determined that these nominees did not necessarily need to be members of the IASL - non-members would be referred to as Associate Members of the research team. After negotiations were concluded, a final list of team members which now includes 22 people was published in May 2012.

A draft research agenda was forwarded to team members on 18 May 2012. Comments from team members will be received until 30 June 2012, at which time a final draft of the research agenda will be submitted to the Board of the IASL for review.

Meetings The research which was discussed during the meeting of the IASL Research SIG on 24 January 2012 is continuing and is making progress. A number of face-toface and online (SKYPE) meetings have been held with the Chair, IASL Research SIG, the ENSIL Foundation and the Royal Tropical Institute (KIT) in Amsterdam to discuss the proposed research. An additional face-to-face meeting will also take place in Lisbon 
on 25 May 2012. A number of school library colleagues have also been approached individually and have been asked for their suggestions and comments.

\section{An international definition of a school library}

Discussions have been held with IASL colleagues regarding an international definition of what a school library actually is. It should be possible to apply this definition to school libraries in developing, emerging and developed countries, in all the IASL world regions. Initially, the following definition was proposed:

The school library should be the beating heart of a school - supporting learning and teaching for the entire school community (Boelens, 2010). A school library is a function, not a place. It is not a book collection. It is not an e-library. It is a service, offering advice, professional development and knowledge of appropriate learning and teaching materials, digital and non-digital. The most important resource services are the human resources. Teacher librarians contribute to quality teaching and authentic learning. (Phillips, 2011). They are qualified to enable all members of the school community to become critical thinkers, independent learners, enthusiastic readers and global citizens able to participate in a democratic, culturally diverse and just society. This is true for both school and university libraries.

A number of colleagues in the Africa region were invited to comment on this definition. They believe that it is important that this definition also includes the following:

- One of the functions of the school library is to teach learners media and information literacy skills.

- The service which the school library provides to the school.

- The promotion of literacy and the love of reading

Furthermore, they suggested that online discussion groups should be asked to review this definition and make suggestions. This suggestion will be followed through.

\section{Preparation of sets of questions}

By the beginning of April 2012, four draft sets of questions, to be answered by students, teachers, school librarians and school leaders were prepared and reviewed by a small number of colleagues. These sets of questions will also will also be sent to the IASL Research Team for comments for its review. These questions were based on a survey which was designed by Anne-Marie Tarter from the Ripon Grammar School, Ripon, North Yorkshire, U.K.. Written permission for the use and adaption of these questions by the IASL Research SIG has been received. 


\section{Initial collection of data from a small (selected) group}

In the meantime, in April 2012, the Chair of the IASL Research SIG received an urgent request from Mr. Daniel Mangale, abcproject, Kenya, requesting urgent assistance in preparing a survey of primary school libraries in rural Kenya. The Ministry of Education in Kenya had requested Mr. Mangale to prepare a report on school libraries in this area, based on research. The report is to be submitted to the Ministry during June 2012. Due to the urgency of the situation and the fact that no other suitable survey material was available, the Chair made a decision to release the sets of questions to Mr. Mangele and his colleague, who, during a two-week period, have collected data from students, teachers, school librarians and school leaders at 19 rural school libraries.

Examination of the data. Data is being collated and reviewed by Dr. Albert Boekhorst, ENSIL Foundation and the Chair of the IASL Research SIG. At this time, Mr. Mangale has been asked to clarify some of the data which has been received.

The following comments are relative to the pilot project in school libraries in rural Kenya, where an initial review of the data which has revealed the following:

Development of a reading culture_is essential. A recent international study in 27 countries provides evidence that access to books is the key to academic achievement (Evans et al., 2010). Many children who use school libraries in developing countries do not have any books at home, hence they rely on the services of the school library.

The pilot study in primary schools in rural Kenya revealed that few books are available to teachers and children, either inside their own homes or in public libraries. They are dependent upon the school library.

- Education quality. The vast majority of interviewees agrees that a good school library adds to the quality of education.

- The importance of language. It has become obvious that some students had difficulty in answering an English language questionnaire. Most students who answered it were 11 years or age or older.

- Time needed to collect data and guidance during data collection. Time needed to be allocated at the schools so that students, teachers, school librarians and school leaders could complete the questionnaire. Also some parties were unfamiliar with any form of data collection and needed guidance. This was provided by Mr. Mangale and his colleague, however this caused a delay in data collection.

Access to ICT and Internet. For the first time in 2007, and again in 2010, the IFLA/FAIFE World Report approached National Libraries, National Library Associations and other library organisations throughout the world and asked them to answer questions about school libraries in their own country. One-hundred-andtwenty-nine countries provided statistics on school libraries; an additional six countries reported that they have school libraries but could not supply reliable statistics (Bothma, ed. 2011). More than 908,000 school libraries, serving more than 540 million children were reported. Also, the 2010 report confirmed that $30 \%$ of these school libraries have internet access and that this percentage is increasing rapidly (Bothma, ed. 2011).

Nevertheless, the pilot survey in primary schools in rural Kenya revealed that there is very poor or no access to ICT and Internet in most schools, in fact some school 
do not even have electricity. At this point in time, reading of online books is not an option in most schools. Even if computers and internet were made available, appropriate training program for their use would need to be put in place.

- Online collection of data. None of the schools concerned had facilities which would have made it possible to collect data online.

- Difference in school systems. Some difference in school systems which affect the collection of data are specific to an individual country. These differences need to be discussed carefully and taken into account in future surveys.

- Some adjustments to the four sets of questions need to be made. Some questions require clarification; other need to be simplified. Also Mr. Mangale has reported the need for more open-ended questions.

- Budget. The lack of a sufficient budget affects the school library collections and facilities.

- School library collections. There is an urgent need for improvement in school library collections. At most schools which were surveyed, there are not enough books in either the local language or in English. In the worst cases, there was not even one book in the school library for each pupil. For this reason, children at the majority of schools cannot take books home. Most books are readers.

- School library facilities. School leaders, teachers, school librarians and pupils consistently mentioned the need for an actual room within the school where the library could be located, plus the lack of shelving and school library furniture.

- Training of school librarians. Although nearly all school librarians are qualified teachers, most of them have received very little or no training in school librarianship. They are, in fact, teachers who have been put in charge of the library. Many of them still have a full teaching workload. In many cases the library is kept open during the school day by pupils who are library monitors. Many school librarians expressed their willingness to attend training program however in many cases:

- a training program is unavailable

0 the school leader did not agree that (further) training is necessary

$\circ$ there is a lack of funding for training

- even the cost of travel to a training program makes attendance impossible.

A final report will be written after all data has been received, collated and reviewed.

\section{Conclusions to the first part of the study and presentation of results}

This survey in Kenya is being used as a pilot for further surveys which are to be carried out by the research group. As mentioned in the Abstract, this study represent "work in progress". It will be very interesting to see whether or not a pilot survey can take place in Mozambique and how results can be compared with the Kenyan survey. However, some information which has been collected in DR Congo confirms some of the Kenyan data. 


\section{Answers to the research questions}

This research represents an attempt by the IASL Research SIG to provide evidence at international level concerning the impact of school librarianship on education in specific parts of the world. It is hoped that the pilot project in Kenya and the proposed pilot in Mozambique will pave the way for further research in different IASL world regions.

The significance of the study at international level is clear, however only time will tell whether or not this kind of research can be put into practice. Funding needs to be sought so that further study can take place.

It is to be hoped that some (initial) useful data and comparisons will demonstrate the international scope and impact of school libraries to all stakeholders, at international level. The use of an international definition of what a school library actually is will be discussed further, as described above. If results of the study are positive, it is expected that this will have great impact on school libraries worldwide.

At this time it is too early to say whether or not this study can be carried out in cooperation with the a divergent group of institutions including (school) library associations, the IASL, the IFLA SLRC Section, ENSIL and KIT. However at this point the IASL, ENSIL and KIT have indicated their willingness to co-operate with the study. The IFLA SLRC will be approached in the near future. Also, IASL members will be asked to approach their national (school) library associations to request their cooperation

An attempt has been made to formulate a list of questions which are applicable to school libraries that operate under many different circumstance and in divergent cultural settings. These sets of questions are still being reviewed by the IASL Research SIG and other partners.

Data collection in different parts of the world and a timeline for data collection will also be discussed and conclusions will be published at a later date.

\section{References}

Boelens, H. (2010) The evolving role of the school library and information centre in education in digital Europe. London : Middlesex University, School of Arts and Education. Accessed on 24 November, 2011: http://eprints.mdx.ac.uk/7329/

Bothma, T. J. (ed.) (2010) IFLA/FAIFE World Report Series, Vol. VIII, IFLA World Report 2010. Accessed on September 30, 2011, from IFLA (International Federation of Library Associations and Institutions): http://www.ifla-worldreport.org/files/uploaded/ifla_wr/IFLA-WR-2010-Analysis-and-Conclusions.pdf

Evans, M.D.R., et al. (2010) Family scholarly culture and educational success: Books and schooling in 27 nations. Reno: Sociology Department, University of Nevada. 
Phillips, Georgia (2011) A School Library Service declaration. The Hub, Australia, national campaign to promote quality school libraries in Australia:

http://www.gopetition.com/petitions/school-library-service-declaration.html 
Reproduced with permission of the copyright owner. Further reproduction prohibited without permission. 